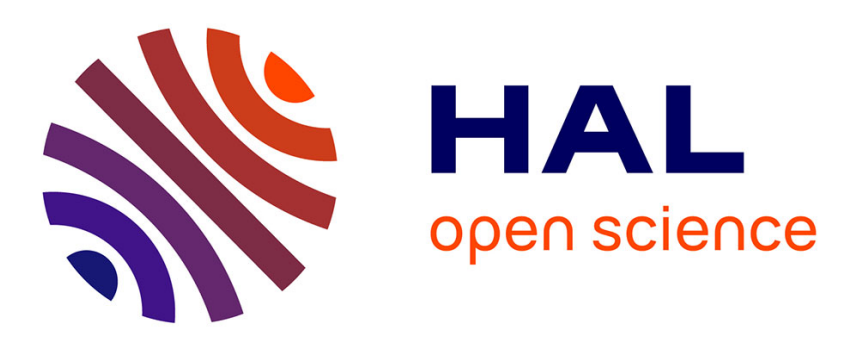

\title{
Effect of the different parts of the interaction potential on the line profile in neutral atom-atom collisions
}

\author{
Nicole F. Allard, Y.G. Biraud
}

\section{To cite this version:}

Nicole F. Allard, Y.G. Biraud. Effect of the different parts of the interaction potential on the line profile in neutral atom-atom collisions. Journal de Physique, 1983, 44 (8), pp.935-943. 10.1051/jphys:01983004408093500 . jpa-00209676

\section{HAL Id: jpa-00209676 https://hal.science/jpa-00209676}

Submitted on 1 Jan 1983

HAL is a multi-disciplinary open access archive for the deposit and dissemination of scientific research documents, whether they are published or not. The documents may come from teaching and research institutions in France or abroad, or from public or private research centers.
L'archive ouverte pluridisciplinaire HAL, est destinée au dépôt et à la diffusion de documents scientifiques de niveau recherche, publiés ou non, émanant des établissements d'enseignement et de recherche français ou étrangers, des laboratoires publics ou privés. 


\title{
Effect of the different parts of the interaction potential on the line profile in neutral atom-atom collisions
}

\author{
N. F. Allard (*) \\ Département d'Astrophysique Fondamentale \\ and Y. G. Biraud (**) \\ Astronomie Infrarouge, Observatoire de Paris-Meudon, 92190 Meudon, France
}

(Reçu le 20 janvier 1983, révisé le 28 mars, accepté le 21 avril 1983)

\begin{abstract}
Résumé. - Les profils de raie du Cs perturbé par du Xe sont calculés dans la théorie unifiée d'Anderson et Talman. La courte portée et la longue portée du potentiel sont représentées par deux potentiels carrés. Nous comparons leurs effets respectifs sur les caractéristiques du profil. Les résultats obtenus permettent de mieux comprendre la physique des collisions.
\end{abstract}

Abstract. - Line profiles of Cs perturbed by Xe are calculated in the unified theory of Anderson and Talman. The short range and the long range parts of the potential are represented by two square-wells. We compare their respective effects on the characteristics of the profile. The results improve our understanding of the collision process.

\section{Introduction.}

In previous works (Allard [1] and Allard and Biraud [2]) we were interested in profiles perturbed by short range potentials. In these studies we used a square-well potential to describe the interaction of the radiator with the perturber. The autocorrelation function was completely analytical [1] and is given in the Appendix. It provided a complete understanding of the characteristics of the satellites and hence of their influence on the line parameters (Gilbert, Allard and Ch'en [3]). For the reasons described in [2] and because of the results obtained we now add a long range interaction represented by a shallow square-well potential (Fig. 1). The calculations are done in the Anderson and Talman theory [4]. The autocorrelation function $\Phi(s)$ is semi-analytical and its expression presents ten different forms depending on the values of the correlation time $s$. The length of the calculation almost prevents any analytical calculations being made for a more sophisticated potential. Note that the expression $\Phi_{i}(s), i=1,10$, even in this "simple" situation, are by far too long to be reported here. They appear in Allard [5]. In section 3 we show that the main effect

(*) CNRS (G.R. 24) Processus Atomiques et Moléculaires de l'Astrophysique. Groupe de Recherche au CNRS.

(**) CNRS (LA 325) Astronomie Infrarouge. Laboratoire Associé au CNRS.

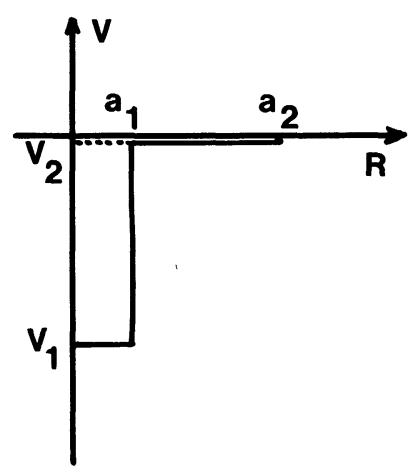

Fig. 1. - Two step-potential.

of the long range potential is to shift the whole profile. The explanation of the origin of this shift needs going back to our square-well studies but now for very weak interactions (sections 4 and 5). The effects of the different potential parameters on the line are studied, reported and explained in great detail (section 6).

\section{Theory.}

The spectral line $I(\omega)$ is the Fourier transform $(F T)$ of the autocorrelation $\Phi(s)$ :

$$
I(\omega)=\frac{1}{2 \pi} \int_{-\infty}^{+\infty} \Phi(s) \mathrm{e}^{i \omega s} \mathrm{~d} s
$$


We use the unified theory of Anderson and Talman and $\Phi(s)$ is calculated with the assumption that the radiators are stationary in space, the perturbers are mutually independent and the potentials are scalarly additive. $\Phi(s)$ is expressed by :

$$
\Phi(s)=\exp -(w(s)+i d(s)),
$$

where

$$
\begin{aligned}
w(s)+i d(s)=n \bar{v} & \int_{0}^{\infty} 2 \pi \rho \mathrm{d} \rho \times \\
& \times \int_{-\infty}^{+\infty}(1-\exp i \eta(\rho, t, s)) \mathrm{d} t
\end{aligned}
$$

$n$ is the perturber density, $\rho$ the impact parameter, $\eta(t, s)$, the phase shift calculated along a classical path :

$$
\eta(t, s)=\int_{t}^{t+s} V\left(t^{\prime}\right) \mathrm{d} t^{\prime}
$$

$V$ represents the difference of the energy levels of the present transition (Fig. 1). We assume rectilinear trajectories for the perturbers of uniform velocity $\bar{v}\left(\bar{v}=\left(\frac{8 k T}{\pi m}\right)^{1 / 2}\right)$. The assumption of mean velocity is not cumpulsory. Effectively we have studied else- where (Allard and Biraud [6]) the influence of the average on velocities and have proved that the fundamental results were not altered when a mean velocity $\bar{v}$ is used.

\section{Effects of the long range part.}

3.1 VARIATION WITH $a_{2} .-\left(a_{1}=6 \times 10^{-8} \mathrm{~cm}\right.$, $\left.V_{1}=-31.8 \mathrm{~cm}^{-1}, V_{2}=-0.05 \mathrm{~cm}^{-1}\right)$. We have studied the characteristics of the profile for different values of $a_{2}$. The results are presented in table $I$. $h_{\text {tot }}=\frac{4}{3} \pi a_{2}^{3} n$ is the number of perturbers in the sphere of radius $a_{2}\left(n=2.77 \times 10^{20}\right.$ atom. $\mathrm{cm}^{-3}$, $T=478 \mathrm{~K})$.

3.1.1 Study of the line. - We can see that for $a_{2}$ varying from $2 \times 10^{-7} \mathrm{~cm}$ to $1.1 \times 10^{-6} \mathrm{~cm}$, the width $w$ increases by a factor 4 when the shift $d$ is multiplied by 200 . The shift is therefore very sensitive to the long range part of the potential $[7,8]$.

In figure 2 we have plotted the variations of $w$ and $d$ with $h$. It is interesting to notice the linear variation of $d$ with $h$. We will explain this behaviour later. The width increases with $a_{2}$ and hence the line intensity decreases because we have normalized the profile area to unity.

3.1.2 Study of the satellite. - The characteristics of the satellite remain unaltered by the addition of the long range potential but are completely determined by the short range potential which proves they

Table I. - Variation of the profile characteristics with $a_{2}$.

\begin{tabular}{|c|c|c|c|c|c|}
\hline $\begin{array}{c}a_{2} \\
\times 10^{-8} \mathrm{~cm}\end{array}$ & $h_{\text {tot }}$ & $\begin{array}{c}w \\
\mathrm{~cm}^{-1}\end{array}$ & $\begin{array}{c}d \\
\mathrm{~cm}^{-1}\end{array}$ & Intensity & $\begin{array}{c}h V \\
\mathrm{~cm}^{-1}\end{array}$ \\
\hline $\begin{array}{c}a_{1}=a_{2}=6 \\
\text { Square-well }\end{array}$ & 0.25 & 1.44 & 0 & 0.35 & \\
\hline 20 & 9.3 & 1.47 & -0.4 & 0.33 & -0.5 \\
\hline 30 & 31 & 1.6 & -1.6 & 0.32 & -1.6 \\
\hline 40 & 74 & 1.8 & -3.8 & 0.29 & -3.9 \\
\hline 50 & 145 & 2.2 & -7.6 & 0.26 & -7.7 \\
\hline 60 & 251 & 2.7 & -13 & 0.22 & -13 \\
\hline 70 & 398 & 3.2 & -21 & 0.19 & -21 \\
\hline 80 & 594 & 3.8 & -32 & 0.17 & -32 \\
\hline 90 & 846 & 4.3 & -45 & 0.15 & -45 \\
\hline 100 & 1160 & 5 & -62 & 0.13 & -62 \\
\hline 110 & 1544 & 5.7 & -82 & 0.12 & -82 \\
\hline
\end{tabular}




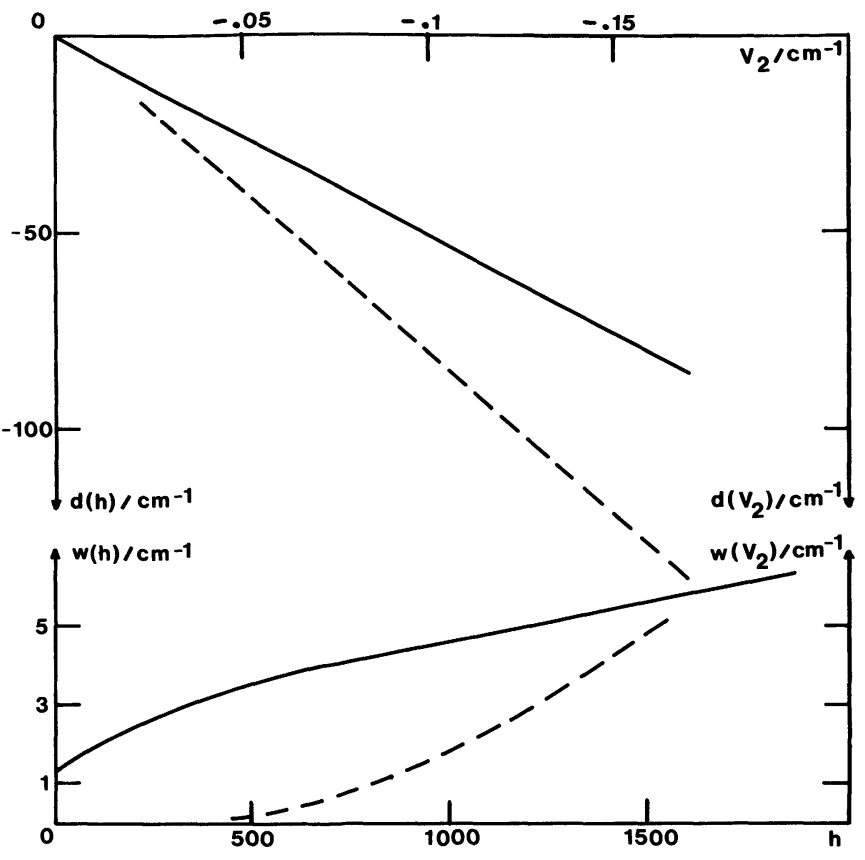

Fig. 2. - Variation of $w$ and $d:$ with $h-$, with $V_{2} \ldots$.

originate from the collision effect. The separation satellite-line remains almost constant and of the order of $30 \mathrm{~cm}^{-1}$ which corresponds to the position of the satellite for the square-well potential $\left(a_{1}, V_{1}\right)$. We exactly note the same phenomena for the width $\left(13.5 \mathrm{~cm}^{-1}\right)$ and absolute intensity $\left(1.3 \times 10^{-2}\right)$ of the satellite which are, again, those obtained with the square-well.

3.2 VARIATION WITH $V_{2} .-\left(a_{1}=6 \times 10^{-8} \mathrm{~cm}\right.$, $a_{2}=2 \times 10^{-7} \mathrm{~cm}, V_{1}=-79.5 \mathrm{~cm}^{-1}$ ). (Same conditions of temperature and density as before.)

The results are presented in table II. The line only is sensitive to $V_{2}$. In figure 2 we have plotted the variation of $w$ and $d$ with $V_{2}$. Notice again the linear variation of $d$ with $V_{2}$. The characteristics of the satellite do not vary with $V_{2}$.

3.3 CoNCLUSION. - We have shown that the important modifications concern the line. The new feature is the shift of the total profile which is observed by spectroscopists [9]. Why does taking into account the distant collisions induce this translation ? It is again the square-well potential model which will answer the question.

\section{Origin of the shift.}

We have calculated the profile perturbed by a squarewell potential of weak interaction. We have obtained (table III) :

i) an important shift of the line $\left(d=-0.49 \mathrm{~cm}^{-1}\right)$ compared to the width $\left(w=0.37 \times 10^{-2} \mathrm{~cm}^{-1}\right)$,

ii) a line which is Lorentzian and whose parameters are exactly the asymptotic ones (impact limit). We had never previously obtained such results because we had never used so shallow a potential.
Table II. - Variation of the profile characteristics with $V_{2}$.

\begin{tabular}{|c|r|r|r|r|}
\hline $\begin{array}{c}V_{2} \\
\times 10^{-2} \mathrm{~cm}^{-1}\end{array}$ & \multicolumn{1}{|c|}{5.3} & \multicolumn{1}{c|}{10.6} & 13.25 & 15.9 \\
\hline Int. & 0.377 & 0.358 & 0.345 & 0.331 \\
\hline$d \mathrm{~cm}^{-1}$ & -0.42 & -0.86 & -1.08 & -1.3 \\
\hline$w \mathrm{~cm}^{-1}$ & 1.31 & 1.39 & 1.46 & 1.54 \\
\hline Asym & 1.07 & 1.07 & 1.07 & 1.07 \\
\hline
\end{tabular}

The results point out clearly that the shift is mainly due to a weak interaction (distant perturbers).

In so weak an interaction the only effect of the collision is a translation. This shift of $-0.49 \mathrm{~cm}^{-1}$ can be compared to $-0.41 \mathrm{~cm}^{-1}$ obtained with the long range potential with the same $\left(a_{2}, V_{2}\right)$. The present value is weaker because :

i) the weak interaction exists only for $\left[a_{1}, a_{2}\right]$

ii) the shift due to the potential $V_{1}$ is an oscillatory quantity. We will come back later to this point. But this translation of the whole profile induces considering the profile as the convolution of the " long range profile" by the "short range profile"

We now precise this last point.

As we have seen before, the profile perturbed by the square well potential $\left(a_{2}, V_{2}\right)$ is very sharp and tends to a Dirac impulse when $V_{2}$ tends to zero.

The arguments of the autocorrelation function are :

$$
w(s)+i d(s)=2 \pi n \bar{v} \int_{0}^{\infty} \rho F(\rho, s) \mathrm{d} \rho .
$$

In the case of a two-step potential, the integral over the impact parameter subdivides into two integrals :

$$
\begin{aligned}
& w(s)+i d(s)=2 \pi n \bar{v} \times \\
& \quad \times\left(\int_{0}^{a_{1}} \rho F_{V_{1}, V_{2}}(\rho, s) \mathrm{d} \rho+\int_{a_{1}}^{a_{2}} \rho F_{V_{2}}(\rho, s) \mathrm{d} \rho\right) .
\end{aligned}
$$

The calculation of the integral between $a_{1}$ and $a_{2}$ is the same as for the square-well potential.

Using equation 4 the autocorrelation function given in (2) becomes :

$$
\Phi(s)=\Phi_{V_{1}, V_{2}}(s) \cdot \Phi_{V_{2}}(s)
$$

and the total profile will be consequently

$$
I(\omega)=F T\left[\Phi_{V_{1}, V_{2}}(s)\right] * F T\left[\Phi_{V_{2}}(s)\right]
$$

where * denotes the convolution.

For a very weak interaction $V_{2}, F T\left[\Phi_{V_{2}}(s)\right]$ can be considered as a Dirac impulse. The resulting profile is therefore nothing but a shifted version of the 
Table III. - Variation of the line parameters with $a_{1}$.

\begin{tabular}{|c|c|c|c|c|c|c|c|c|}
\hline & \multicolumn{2}{|c|}{$\begin{array}{c}\text { Square-well potential } \\
\quad\left(a_{1}, V_{1}\right) \\
\left(V_{1}=-31.8 \mathrm{~cm}^{-1}\right)\end{array}$} & \multicolumn{2}{|c|}{$\begin{array}{c}\text { Square-well potential } \\
\quad\left(a_{2}, V_{2}\right) \\
\left(a_{2}=2 \times 10^{-7} \mathrm{~cm}\right. \\
\left.V_{2}=-0.05 \mathrm{~cm}^{-1}\right)\end{array}$} & \multicolumn{4}{|c|}{$\begin{array}{l}\text { Two-step potential } \\
\left(a_{1}, V_{1} ; a_{2}, V_{2}\right)\end{array}$} \\
\hline $\begin{array}{c}a_{1} \\
\times 10^{-8} \mathrm{~cm}\end{array}$ & $\begin{array}{c}w \\
\mathrm{~cm}^{-1}\end{array}$ & $\begin{array}{c}d \\
\mathrm{~cm}^{-1}\end{array}$ & $\begin{array}{c}w \\
\mathrm{~cm}^{-1}\end{array}$ & $\begin{array}{c}d \\
\mathrm{~cm}^{-1}\end{array}$ & ${ }^{1} w$ & $\begin{array}{l}{ }^{2} w \\
\mathrm{~cm}^{-1}\end{array}$ & $\underset{\mathrm{cm}^{-1}}{d}$ & ${ }^{2} d$ \\
\hline 2 & 0.16 & $2.5 \times 10^{-2}$ & $3.6 \times 10^{-2}$ & -0.492 & 0.16 & $\frac{3.6}{0.19} \times 10^{-2}$ & $\begin{aligned} 2.5 \times 10^{-2} & -0.46\end{aligned}$ & -0.48 \\
\hline 3 & 0.32 & $-3.5 \times 10^{-2}$ & & & 0.32 & $\begin{array}{l}3.52 \times 10^{-2} \\
0.35\end{array}$ & $\begin{aligned}-3.5 \times 10^{-2} & -0.51\end{aligned}$ & -0.475 \\
\hline 4 & 0.64 & $4.4 \times 10^{-2}$ & & & 0.64 & $\begin{array}{l}3.4 \times 10^{-2} \\
0.67\end{array}$ & $\begin{aligned} 4.8 \times & 10^{-2} \\
& -0.415\end{aligned}$ & -0.460 \\
\hline 5 & 0.86 & $-4.9 \times 10^{-2}$ & & & 0.86 & $\begin{array}{l}3.2 \times 10^{-2} \\
0.89\end{array}$ & $\begin{aligned} 4.8 \times 10^{-2} & \\
& -0.495\end{aligned}$ & -0.447 \\
\hline 6 & 1.44 & $5.2 \times 10^{-2}$ & & & 1.42 & $\begin{array}{l}3 \times 10^{-2} \\
1.45\end{array}$ & $\begin{array}{r}6 \times 10^{-2} \\
-0.366\end{array}$ & -0.427 \\
\hline
\end{tabular}

profile $F T\left[\Phi_{V_{1}, V_{2}}(s)\right]$. Moreover, we have already noticed that all the profile characteristics are not modified very much except for the apparition of the shift.

$F T\left[\Phi_{V_{1}, V_{2}}(s)\right]$ is to the first-order approximation \#FT $\left[\Phi_{V_{1}}(s)\right]$.

When a weak interaction is added, and only in this case, the profile obtained is the " short range " profile translated. We will see now, from the theoretical expression of the autocorrelation function, that, when using a square-well potential, the profile perturbed by a weak interaction is Lorentzian. (Eqs. $6 a, 6 b$, $7 a, 7 b$ of [1] given in Appendix). The satellites have disappeared independently of the number of interacting perturbers. Then we will see that the approximation $F T\left[\Phi_{V_{1}, V_{2}}(s)\right] \# F T\left[\Phi_{V_{1}}(s)\right]$ is valid when $V_{2}$ is weak.

\section{Analysis of profiles perturbed by a weak interaction in the square - well potential approximation.}

We have studied the variation of the shift with $V$, i.e. with $x=2 a V / v$. We can see on figure 3 that the shift of the profile is identical to the impact shift when $x$ is small. For a given number of perturbers $h_{i}$ it deviates from the impact shift beyond $x=x_{i}$ because of the influence of a near satellite. When the impact shift starts to oscillate, the line shift decreases until $x=x_{\min }$ and then increases because the satellite distance is larger and larger when the interaction increases. We will see later that the impact approximation becomes valid again and the oscillating behaviour appears. The same phenomena are encountered for the width.

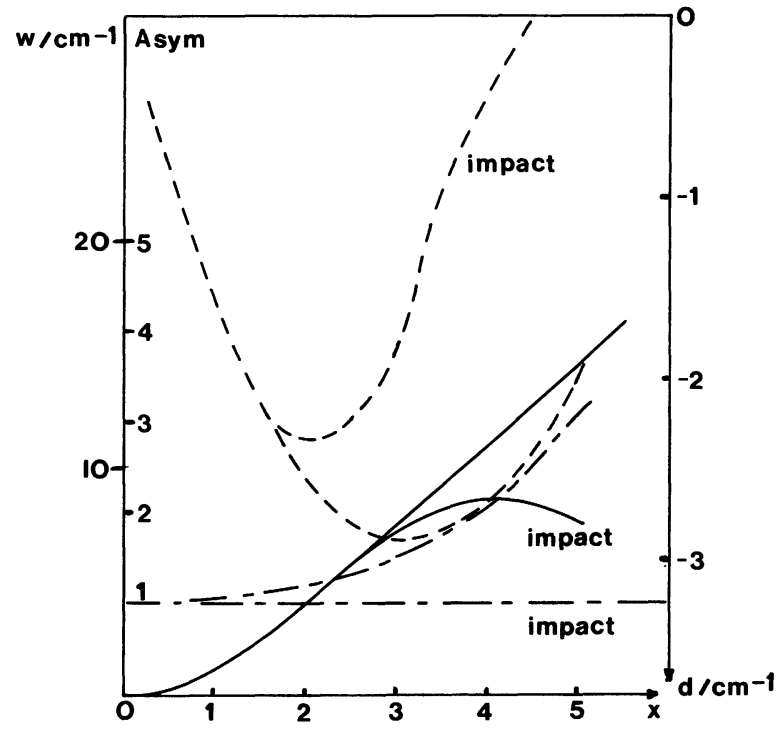

Fig. 3. - Variation with $x$ of : $w-; d---$; Asymmetry - - $\left(h_{i}=0.84\right)$.

The asymmetry $\left({ }^{1}\right)$ is the parameter which is the most sensitive to the influence of the satellite. It is greater than 1 even for very weak $x$.

As we have seen in figure 4 of [2], the variation of the shift with $h$ presents a discontinuity for strong interactions. For decreasing interactions the discontinuity

( $\left.{ }^{1}\right)$ The asymmetry is defined as :

Red half width Blue half width 


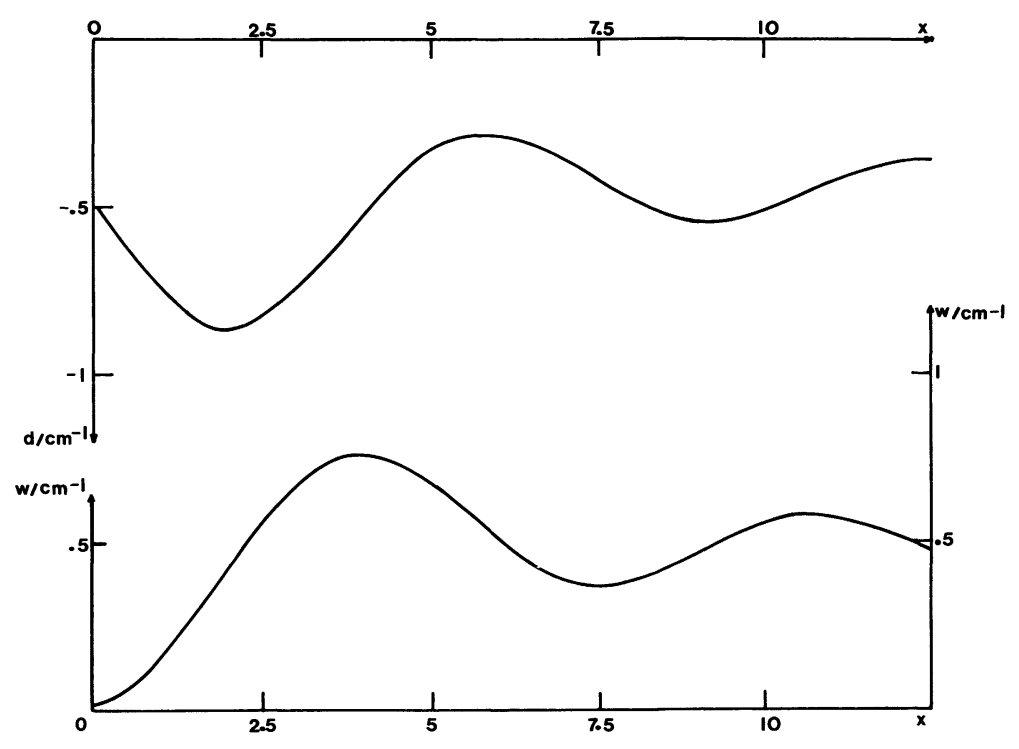

Fig. 4. - Variation of $w$ and $d$ with $x\left(x=\frac{2 a V_{1}}{\bar{v}}\right)$

smoothes out and then completely disappears and the variation of the shift becomes linear. This leads us to expand $w(s)$ and $d(s)$ given by equations 6 and 7 of [1] (given in the Appendix) with respect to $x(u=$ $\bar{v} s / 2 a$ ). We obtain :

$$
u \leqslant 1 \quad\left\{\begin{array}{l}
w_{1}(u)=h x^{2} \frac{u^{2}}{2}\left(1-\frac{u}{2}+\frac{u^{3}}{20}\right) \\
d_{1}(u)=-h x u+h x^{3}\left(\frac{u^{3}}{6}-\frac{u^{4}}{8}+\frac{u^{6}}{60}\right) \\
w_{2}(u)=h \frac{x^{2}}{2}\left(\frac{3}{4} u-\frac{1}{5}\right) \\
d_{2}(u)=-h x u+\frac{h}{10} x^{3} u-h \frac{x^{3}}{24} .
\end{array}\right.
$$

$d_{1}$ and $d_{2}$ are identical to the first order to $-h V_{2}$; it is why we obtained the impact shift.

For weak interactions the profile becomes Lorentzian with a very small width and is shifted by $d_{\text {impact }}$.

The oscillations which give rise to the satellites disappear. We have shown in a theoretical calculation that the only effect of a weak interaction is to shift the line.

We have seen in 3.1.1. and 3.2 that the shift is linear with $h$ and $V_{2}$. So the approximation

$$
d \#-h V_{2}
$$

is valid for the two-step potential. In table I we compare the line shift to $h V_{2}$. The agreement is remarkable particularly for large values of $a_{2}$.

\section{Study of the effect of the different parameters of the potential on the width and shift.}

6. 1 VARIATION WITH $a_{1}$. - In order to clearly define the contributions of the short range part and of the long range part of the potential to the line parameters we have compared the theoretical widths and shifts given by the impact limit for the following potentials :

$$
\begin{aligned}
\text { Square-well potentials : } & \left\{\begin{array}{lll}
V=V_{1} & \text { for } & R \leqslant a_{1} \\
V=0 & & R>a_{1}
\end{array}\right. \\
\text { Two-step potential : } & \left\{\begin{array}{lll}
V=V_{2} & \text { for } & R \leqslant a_{2} \\
V=0 & R>a_{2}
\end{array}\right. \\
& \left\{\begin{array}{lll}
V=V_{1} & \text { for } & R \leqslant a_{1} \\
V=V_{2} & a_{1}<R \leqslant a_{2} \\
V=0 & R>a_{2}
\end{array}\right.
\end{aligned}
$$

For the last potential case we have split up $w$ and $d$ into :

$-{ }^{1} w$ and ${ }^{1} d$ obtained for collisions of impact parameter $\rho \leqslant a_{1} ;{ }^{1} w$ and ${ }^{1} d$ are functions of $V_{1}$ and $V_{2}$.

$-{ }^{2} w$ and ${ }^{2} d$ obtained for collisions of impact parameter $a_{1} \leqslant \rho \leqslant a_{2} ;{ }^{2} w$ and ${ }^{2} d$ are only functions of $V_{2}$.

We can see in table III that the width is given mainly by the strong interaction which was the physical idea of Weisskopf [10] who considered that the broadening arises essentially from collisions which cause phase changes of $\eta \geqslant 1$.

We have studied a series of two-step potentials for which all the parameters are fixed except $a_{1}$. The variation range of $a_{1}$ has been chosen such that we cover the range from case 1 (quasi-pure weak interaction) to case 2 (strong and weak interactions). The results are presented in table IV. The shift decreases slightly but remains of the same order of magnitude. On the contrary the width increases drastically as soon as the strong interaction zone becomes important.

In table $\mathrm{V}$ we compare the widths and shifts given by the impact approximation (for square-well and 
Table IV. - Variation of the line parameters with $a_{1}$.

\begin{tabular}{|c|c|c|}
\hline $\begin{array}{c}a_{1} \\
\mathrm{~cm}\end{array}$ & $\begin{array}{c}w \\
\mathrm{~cm}^{-1}\end{array}$ & $\begin{array}{c}d \\
\mathrm{~cm}^{-1}\end{array}$ \\
\hline $10^{-13}$ & $3.58 \times 10^{-2}$ & 0.47721 \\
\hline $10^{-12}$ & $3.58 \times 10^{-2}$ & 0.47721 \\
\hline $10^{-11}$ & $3.58 \times 10^{-2}$ & 0.47721 \\
\hline $10^{-10}$ & $3.58 \times 10^{-2}$ & 0.47721 \\
\hline $10^{-9}$ & $3.58 \times 10^{-2}$ & 0.47719 \\
\hline $10^{-8}$ & $8.6 \times 10^{-2}$ & 0.475 \\
\hline $2 \times 10^{-8}$ & 0.19 & 0.470 \\
\hline $3 \times 10^{-8}$ & 0.34 & 0.46 \\
\hline $5 \times 10^{-8}$ & 0.86 & 0.43 \\
\hline $6 \times 10^{-8}$ & 1.41 & 0.41 \\
\hline
\end{tabular}

two-step potentials) to those measured on the profiles computed as the $F T$ of the autocorrelation. The shift is oscillatory because of ${ }^{1} d .^{2} d$ decreases with increasing $a_{1}$ as the part of the long range decreases.
In table VI we notice that the width of the satellite decreases due to the increase of the collision-time. The distance line-satellite tends to its theoretical value of $-79.6 \mathrm{~cm}^{-1}$.

6.2 VARIATION WITH $V_{1}$. - In table VII we have compared the impact line parameters when using :

i) the square-well potential $\left(a_{1}, V_{1}\right)$

ii) the two-step potential $\left(a_{1}, V_{1} ; a_{2}, V_{2}\right)$.

For the last potential we have split up $w$ and $d$ into :

$$
-{ }^{1} w \text { and }{ }^{1} d\left(\rho \leqslant a_{1}\right)
$$

$-{ }^{2} w$ and ${ }^{2} d\left(a_{1} \leqslant \rho \leqslant a_{2}\right)$ which remain equal to $0.015 \mathrm{~cm}^{-1}$ and $-0.45 \mathrm{~cm}^{-1}$ respectively $\left(\left(a_{2}, V_{2}\right)\right.$ do not vary).

We have plotted (Fig. 4) the variations of $w$ and $d$ with $x$. We have the same tapered oscillating behaviour described in $\S 5$ for the square-well potential. The limit value for the shift is $d_{2}=-0.45 \mathrm{~cm}^{-1}$ which was easily predictable. We have verified that the line parameter $w_{\mathrm{sw}}$ and $d_{\mathrm{sw}}$ of the profiles obtained by the Fourier transform of the autocorrelation function when using the square-well potential have the same behaviour as the impact parameters $w_{\text {impsw }}$ and $d_{\text {impsw }}$ which proves that the study was possible in the impact limit.

\section{Effect of the temperature on the profiles calculated with the two-step potential.}

Just as in [6] we study here the effect of temperature on the profiles. We make calculations for the same

Table V. - Variation of the line parameters with $a_{1}$.

\begin{tabular}{|c|c|c|c|c|c|c|c|c|c|}
\hline & \multicolumn{2}{|c|}{$\begin{array}{c}\text { Square-well potential } \\
\qquad\left(a_{1}, V_{1}\right) \\
\left(a_{1}=6 \times 10^{-8} \mathrm{~cm}\right. \\
\left.V_{1}=-31.8 \mathrm{~cm}^{-1}\right)\end{array}$} & \multicolumn{2}{|c|}{$\begin{array}{l}\text { Square-well potential } \\
\qquad \begin{array}{c}\left(a_{2}, V_{2}\right) \\
\left(a_{2}=3 \times 10^{-7} \mathrm{~cm},\right. \\
\left.V_{2}=-0.05 \mathrm{~cm}^{-1}\right)\end{array}\end{array}$} & \multicolumn{5}{|c|}{$\begin{array}{l}\text { Two-step potential } \\
\left(a_{1}, V_{1} ; a_{2}, V_{2}\right)\end{array}$} \\
\hline $\begin{array}{c}a_{1} \\
\times 10^{-8} \mathrm{~cm}\end{array}$ & $\begin{array}{c}w \\
\mathrm{~cm}^{-1}\end{array}$ & $\underset{\mathrm{cm}^{-1}}{d}$ & $\begin{array}{c}w \\
\mathrm{~cm}^{-1}\end{array}$ & $\begin{array}{c}d \\
\mathrm{~cm}^{-1}\end{array}$ & ${ }^{1} w{ }_{\mathrm{cm}^{-1}}^{w}{ }^{2} w$ & $\begin{array}{l}w \text { calc } \\
\mathrm{cm}^{-1}\end{array}$ & ${ }^{1} d \quad \underset{\mathrm{cm}^{-1}}{d}$ & ${ }^{2} d$ & $\begin{array}{l}d \text { calc } \\
\mathrm{cm}^{-1}\end{array}$ \\
\hline 6 & 1.44 & $5.2 \times 10^{-2}$ & 0.18 & 66 & $\begin{array}{c}1.420 .17 \\
1.6\end{array}$ & 1.44 & $\begin{array}{r}6.4 \times 10^{-2} \\
-1.5\end{array}$ & -1.56 & -1.6 \\
\hline 7 & 1.68 & $-5 \times 10^{-2}$ & & & $\begin{array}{c}1.680 .166 \\
1.84\end{array}$ & 1.9 & $\begin{array}{c}-5 \times 10^{-2} \\
-1.57\end{array}$ & -1.52 & -1.6 \\
\hline 7.5 & 2.18 & $-7.9 \times 10^{-2}$ & & & $\begin{array}{c}2.180 .164 \\
2.34\end{array}$ & 2.22 & $\begin{array}{r}-6.3 \times 10^{-2} \\
-1.57\end{array}$ & -1.5 & 1.6 \\
\hline 8 & 2.54 & $4.5 \times 10^{-2}$ & & & $\begin{array}{c}2.520 .16 \\
2.68\end{array}$ & 2.50 & $\begin{array}{r}6.6 \times 10^{-2} \\
-1.42\end{array}$ & -1.48 & -1.6 \\
\hline 9 & 2.8 & $-3.6 \times 10^{-2}$ & & & $\begin{array}{c}2.76 \quad 0.154 \\
2.91\end{array}$ & 3.1 & $\begin{array}{c}3.4 \times 10^{-2} \\
-1.47\end{array}$ & -1.44 & -1.6 \\
\hline 10 & 3.9 & $2.3 \times 10^{-2}$ & & & $\begin{array}{cc}3.8 & 0.144 \\
3.94\end{array}$ & 3.83 & $\begin{array}{c}5 \times 10^{-2} \\
-1.34\end{array}$ & -1.39 & -1.6 \\
\hline
\end{tabular}


Table VI. - Variation of the characteristics of the profile with $a_{1}$.

\begin{tabular}{|c|c|c|c|c|c|c|c|c|}
\hline $\begin{array}{c}a_{1} \\
\times 10^{-8} \mathrm{~cm}\end{array}$ & $\begin{array}{c}w \\
\mathrm{~cm}^{-1}\end{array}$ & $\begin{array}{c}d \\
\mathrm{~cm}^{-1}\end{array}$ & Int. & $\begin{array}{c}\text { Position } \\
\mathrm{cm}^{-1}\end{array}$ & $\begin{array}{c}\omega_{\text {sat }}-\omega_{\text {line }} \\
\mathrm{cm}^{-1}\end{array}$ & $\begin{array}{l}\text { width } \\
\mathrm{cm}^{-1}\end{array}$ & Abs. Int. & Rel. Int./line \\
\hline 6 & 1.44 & -1.6 & 0.35 & -80.6 & -79 & 13.2 & & \\
\hline 7 & 1,90 & -1.6 & 0.228 & -80.8 & -79.2 & 11.6 & $1.8 \times 10^{-2}$ & $8 \times 10^{-2}$ \\
\hline 7.5 & 2.22 & -1.6 & 0.18 & -80.8 & -79.2 & 11 & $2.1 \times 10^{-2}$ & 0.12 \\
\hline 8 & 2.49 & -1.6 & 0.143 & -80.8 & -79.2 & 10.6 & $2.4 \times 10^{-2}$ & 0.17 \\
\hline 9 & 3.1 & -1.6 & 0.089 & -81 & -79.4 & 10 & $2.72 \times 10^{-2}$ & 0.31 \\
\hline 10 & 3.83 & -1.6 & 0.053 & -81 & -79.4 & 9.8 & $2.74 \times 10^{-2}$ & 0.51 \\
\hline
\end{tabular}

Table VII. - Variation of the line parameters with $V_{1}$.

\begin{tabular}{|c|c|c|c|c|c|c|c|c|}
\hline $\begin{array}{c}V_{1} \\
\mathrm{~cm}^{-1}\end{array}$ & $\begin{array}{r}w_{\mathrm{sw}} \\
\mathrm{cm}^{-1}\end{array}$ & $\underset{\mathrm{cm}^{-1}}{d_{\mathrm{Sw}}}$ & $\begin{array}{l}w_{\text {impsw }} \\
\mathrm{cm}^{-11}\end{array}$ & $\begin{array}{l}d_{\text {impsw }} \\
\mathrm{cm}^{-1}\end{array}$ & $\begin{array}{c}{ }^{1} w \\
\mathrm{~cm}^{-1}\end{array}$ & $\begin{array}{c}1 d \\
\mathrm{~cm}^{-1}\end{array}$ & $\begin{array}{c}w \\
\mathrm{~cm}^{-1}\end{array}$ & $\underset{\mathrm{cm}^{-1}}{d}$ \\
\hline-0.2 & & & $2 \times 10^{-3}$ & $-3 \times 10^{-2}$ & $10^{-2}$ & $-7 \times 10^{-2}$ & $4 \times 10^{-2}$ & -0.51 \\
\hline-0.5 & & & $1.4 \times 10^{-2}$ & $-7.6 \times 10^{-2}$ & $3 \times 10^{-2}$ & -0.11 & $6 \times 10^{-2}$ & -0.56 \\
\hline-1.1 & & & $6 \times 10^{-2}$ & -0.15 & $8 \times 10^{-2}$ & -0.18 & 0.12 & -0.63 \\
\hline-2.1 & & & 0.2 & -0.28 & 0.26 & -0.30 & 0.30 & -0.75 \\
\hline-3.2 & & & 0.46 & -0.37 & 0.52 & -0.38 & 0.56 & -0.83 \\
\hline-4.2 & & & 0.74 & -0.49 & 0.80 & -0.41 & 0.84 & -0.86 \\
\hline-5.3 & 1.02 & -0.4 & 1.02 & -0.38 & 1.08 & -0.38 & 1.1 & -0.82 \\
\hline-7.4 & & & 1.4 & -0.22 & 1.44 & -0.2 & 1.46 & -0.65 \\
\hline-10.6 & 1.36 & $2 \times 10^{-2}$ & 1.33 & $9 \times 10^{-2}$ & 1.22 & 0.1 & 1.34 & -0.34 \\
\hline-12.7 & & & 1 & 0.15 & 0.98 & 0.16 & 1.02 & -0.29 \\
\hline-15.9 & 0.77 & $2 \times 10^{-2}$ & 0.71 & $2.7 \times 10^{-2}$ & 0.70 & $2 \times 10^{-2}$ & 0.74 & -0.42 \\
\hline-18 & & & 0.79 & $-8 \times 10^{-2}$ & 0.80 & $-8 \times 10^{-2}$ & 0.82 & -0.53 \\
\hline-21.2 & 1.05 & $-8 \times 10^{-2}$ & 1.06 & $-7.2 \times 10^{-2}$ & 1.06 & $-7 \times 10^{-2}$ & 1.1 & -0.51 \\
\hline-23.3 & & & 1.1 & $8 \times 10^{-3}$ & 1.1 & $2 \times 10^{-2}$ & 1.14 & -0.43 \\
\hline-26.5 & 0.94 & $6 \times 10^{-2}$ & 0.93 & $7.4 \times 10^{-2}$ & 1 & $7 \times 10^{-2}$ & 1.02 & -0.37 \\
\hline-31.8 & & & 0.86 & $-5 \times 10^{-2}$ & 0.86 & $-5 \times 10^{-2}$ & 0.89 & -0.50 \\
\hline
\end{tabular}


range of temperatures as in [6] : 16 to $3530 \mathrm{~K}$. The results are similar to those reported in [6]. The only change for the profile is its translation. The shift remaining constant when the temperature varies : we have seen in $\S 5$ that the shift is proportional to the first order to $h V$ which is not temperature dependent. This has been reported by Ch'en and Garret [11]

\section{Conclusion.}

As in our previous papers ([1] and [2]) we have deliberately used a 4-parameter model of the potential which allowed us to isolate the influence of each parameter on the profile characteristics.

To interpret the effects of the long range part of the potential we have been obliged to study the square well-potential again. But now for a weak interaction, we have split the autocorrelation into two parts :

- one for strong interactions (small impact parameters)
- the other for weak interactions (large impact parameters).

This allows the following interpretation of the computed profiles : the profile can be considered to a very good approximation as the convolution of the strong interaction square-well potential profile by the weak and distant interaction square-well potential profile. The latter can almost be regarded as a Dirac impulse whose unique effect is the shift of the whole profile, the satellite remaining unchanged.

We have pointed out that the satellite is sensitive to the deep part of the potential and is due to the formation of the pseudo-molecule. On the other hand the description of the main line requires knowing the whole potential shape.

We can conclude that again a very simple two-step potential is sufficient to understand completely and describe qualitatively the line shapes observed in neutral atom-atom collisions.

\section{Appendix.}

We report here equations (6) and (7) of [1] which appear in the autocorrelation :

$$
\Phi(s)=\exp -[w(s)+i d(s)] .
$$

If we define the following dimensionless variables

$$
\begin{aligned}
& u=\frac{\bar{v} s}{2 a}, \\
& x=\frac{2 a V}{\bar{v}}=V \tau_{\max }, \\
& h=\frac{4}{3} \pi a^{3} n .
\end{aligned}
$$

we obtain two different expressions of $w$ and $d$.

For $u<1$ :

$$
\begin{aligned}
& w_{1}(u)=h\left\{1-\cos (x u)+3\left[u\left(\frac{1}{x^{2}}+\frac{1}{2}\right)+u \cos (x u)\left(\frac{1}{2}+\frac{3}{x^{2}}-\frac{u^{2}}{6}\right)+\frac{\sin (x u)}{x}\left(u^{2}-1-\frac{4}{x^{2}}\right)\right]\right\} \\
& d_{1}(u)=h\left\{-\frac{3}{x}\left(1+\frac{4}{x^{2}}\right)-\sin (x u)+3\left[u \sin (x u)\left(\frac{1}{2}-\frac{u^{2}}{6}+\frac{3}{x^{2}}\right)+\frac{\cos (x u)}{x}\left(1+\frac{4}{x^{2}}-u^{2}\right)\right]\right\},
\end{aligned}
$$

and for $u \geqslant 1$,

$$
\begin{aligned}
& w_{2}(u)=\frac{3}{2} h u\left(1+\frac{2}{x^{2}}(1-\cos x-x \sin x)\right)+h\left\{1+\frac{12}{x^{3}}\left[x \cos x+\sin x\left(\frac{x^{2}}{4}-1\right)\right]\right\}, \\
& d_{2}(u)=3 h \frac{u}{x^{2}}(x \cos x-\sin x)-\frac{12 h}{x}\left\{\frac{1}{4}+\frac{1}{x^{2}}\left[1+\cos x\left(\frac{x^{2}}{4}-1\right)-x \sin x\right]\right\} .
\end{aligned}
$$




\section{References}

[1] Allard, N. F., J. Phys. B. 11 (1978) 1383.

[2] Allard, N. F. and Biraud, Y. G., J. Quant. Spectros. Radiat. Transfer 23 (1980) 253.

[3] Gilbert, D. E., Allard, N. F. and Ch'en, S. Y., J. Quant. Spectros. Radiat. Transfer 23 (1980) 201.

[4] Anderson, P. W. and Talman, J. D., Proc. Conf. Broadening of Spectral Lines (Bell Telephone System Technical Publications, $n^{\circ} 3117,29$, Murray Hill, N. J.) (1956).

[5] Allard, N. F., Rapport interne.
[6] Allard, N. F. and Biraud, Y. G., J. Physique 43 (1982) 501.

[7] Sahal-Brechot, S., Astron. Astrophys. 2 (1969) 322.

[8] Allard, N. F., Sahal-Brechot, S. and Biraud, Y. G., J. Phys. B. 7 (1974) 2158.

[9] Spielfiedel, A., Gilbert, D., RouefF, E. and Rostas, F., J. Phys. B 12 (1979) 3693.

[10] Weisskopf, V., Phys. Z. 34 (1933) 1.

[11] Ch'en, S. Y. and Garret, R. O., Phys. Rev. 144 (1966) 59. 